\title{
Erratum to: NMR Reinvestigation of the Caffeine-Chlorogenate Complex in Aqueous Solution and in Coffee Brews
}

\author{
Nicola D'Amelio • Luca Fontanive • Fulvio Uggeri • \\ Furio Suggi-Liverani $\cdot$ Luciano Navarini
}

Published online: 28 January 2010

(C) Springer Science+Business Media, LLC 2010

Erratum to: Food Biophysics 4(4):321-330

DOI 10.1007/s11483-009-9130-y

In the original version of this article, one affiliation is missing. Complete affiliation is given here.

The online version of the original article can be found at http://dx.doi. org/10.1007/s11483-009-9130-y.

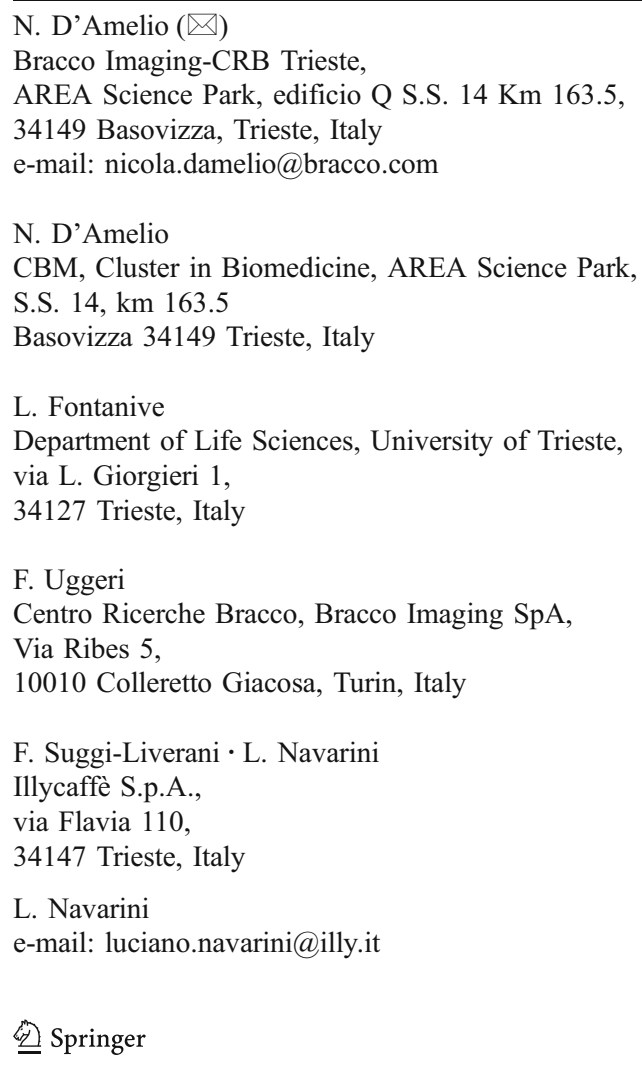

